\title{
Fandom como instrumento de ação cultural: a produção participativa e o compartilhamento nas bibliotecas públicas brasileiras
}

\author{
Bruna Daniele de Oliveira Silva \\ Mestranda; Universidade Estadual Paulista Júlio de Mesquita Filho, Marília, SP, Brasil; \\ bruna.daniele.silva@alumni.usp.br \\ Deise Maria Antonio Sabbag \\ Doutora; Universidade de São Paulo, Ribeirão Preto, SP, Brasil; \\ deisesabbag@usp.br
}

\begin{abstract}
Resumo: As bibliotecas públicas brasileiras são percebidas como depósitos de livros que servem a uma parcela seleta da sociedade. Em contraponto, o fandom constitui-se de indivíduos com interesses em comum, isto é, seus membros desenvolvem de forma colaborativa suas atividades. O artigo objetiva investigar a relação dos fandoms com as bibliotecas públicas brasileiras e verificar, após análise dos dados, se as atividades de fandoms são aplicáveis nessas instituições. A pesquisa tem caráter descritivo-exploratório com abordagem qualitativoquantitativa. Para coleta de dados, foi aplicado questionário por meio dos formulários do Google. Como método de análise, foi utilizada a análise de conteúdo categorial, a partir de estudo estruturado do conteúdo. Os dados coletados demonstram que $59 \%$ dos respondentes não conhecem o conceito de fandom, $82 \%$ acreditam que há demanda por novas atividades na biblioteca e $84 \%$ consideram possível desenvolver atividades de fandom apenas com os recursos atuais. As atividades de fandom estão diretamente ligadas à leitura, à escrita e ao desenvolvimento de diversas competências importantes para o indivíduo, tais como os letramentos informacional e digital. Portanto, sua aplicação na biblioteca pública, além de fomentar o uso desse espaço, pode engajar leitores e a comunidade e promover a sociabilidade, isso pode convertêla em um instrumento de transformação social.
\end{abstract}

Palavras-chave: Bibliotecas públicas. Fandom. Ação cultural. Cultura participativa. Trabalho colaborativo.

\section{Introdução}

A comunidade de fãs, também chamada fandom, conquistou definitivamente seu espaço na cultura popular. $O$ desenvolvimento das tecnologias de compartilhamento e comunicação de conteúdos possibilitou que a produção de fãs obtivesse um alcance inédito. $\mathrm{O}$ desenvolvimento de produtos de fãs baseia- 
se em trabalho colaborativo e em cultura participativa. Devido a essas características, o fandom é elencado como uma tendência para a Biblioteconomia, de acordo com as top trends da American Library Association - ALA (2016).

Nesse contexto, as bibliotecas públicas - BPs - são instituições com um enorme potencial de transformação social. É nessas instituições que o indivíduo pode desenvolver capacidades e habilidades para exercer cidadania. Não há dúvidas de que a leitura é um ponto determinante para inserção de um indivíduo na sociedade. Ela influencia diretamente o exercício de seus direitos e a garantia de dignidade.

A população brasileira não tem o hábito de ler. A pesquisa Retratos da leitura no Brasil, desenvolvida pelo Instituto Pró-livro (2016), revela a percepção dos brasileiros quanto às bibliotecas: $71 \%$ da amostra acreditam que a biblioteca é um lugar para estudar ou pesquisar, seguidos de $29 \%$ que veem a biblioteca como um lugar para emprestar livro. Boa parte da população (66\%) não tem o hábito de frequentar qualquer tipo de biblioteca, apenas $8 \%$ utilizam a BP para a leitura e somente $7 \%$ têm a BP como principal forma de acesso ao livro. A amostra ainda elencou fatores que motivariam o uso desses espaços, entre eles: ter mais livros ou títulos novos (32\%), ter títulos interessantes ou que me agradem (22\%) e ter atividades culturais (15\%). Os dados da pesquisa apontam que a população brasileira, no geral, não conhece o espaço da biblioteca, não sabe qual a finalidade dessa instituição e não se sente motivada a frequentá-la. O último dado (15\% gostariam de atividades culturais) é um indício de que as BPs precisam mudar sua imagem frente à comunidade e inserir outras atividades que tirem o livro como único foco dessa instituição.

Nessa perspectiva, o fandom se apresenta como uma ferramenta para atrair novos públicos às BPs, para fomentar o uso dos espaços da biblioteca para novas atividades e para engajar a leitura através de novas fontes de conteúdo para além do livro.

A pesquisa teve como objetivo investigar a relação atual dos fandoms com as bibliotecas públicas brasileiras e verificar a possibilidade da implementação de suas atividades nesses ambientes. A metodologia partiu de uma abordagem descritiva e exploratória de natureza qualitativo-quantitativa. 
Foi aplicado questionário nas BPs cadastradas no Sistema Nacional de Bibliotecas Públicas - SNBP - para coleta de dados.

\section{A comunidade de fãs: os fandoms}

Para Jenkins (2015), quando os fãs se organizam em grupos com objetivos em comum, constituem uma instituição que debate exaustivamente produtos da cultura midiática, além de produzir textos sobre um cânone ou sobre a própria comunidade. Ele explica:

O fandom organizado é, talvez acima de tudo, uma instituição de teoria e crítica, um espaço semiestruturado onde interpretações concorrentes e avaliações de textos comuns são propostas, debatidas e negociadas e onde os leitores especulam quanto à natureza da mídia de massa e sua própria relação com ela. (JENKINS, 2015, p. 100).

A definição de fandom, segundo Hills (2015), ainda não é absoluta, pois os diversos fandoms são formados por diferentes indivíduos inseridos em distintos contextos, podendo significar várias coisas em uma multiplicidade de microcontextos e de momentos interativos sociais e em plataformas distintas. $\mathrm{O}$ fandom é, portanto, performático, isto é, ele assume sentidos distintos conforme se modificam seus atores e contextos.

Hills (2015) rejeita a definição binária de fandom que foi proposta em artigo postado em um fórum de fãs. O usuário autodenominado Obsession_Inc (2009) divide o fandom em dois tipos: o fandom afirmativo e o fandom transformativo. O primeiro classifica-se como afirmativo, pois são fãs envolvidos na produção textual que tendem a reafirmar o cânone, ou seja, eles dão continuidade à narrativa sem fazer grandes mudanças nas principais características tanto do universo quanto dos personagens. O segundo, fandom transformativo, tem como principal característica as modificações expressivas feitas no cânone, por exemplo, formar um casal improvável ou modificar a personalidade de um personagem. O artigo de Obsession_Inc (2009) sustenta que no fandom afirmativo a maioria dos integrantes são do gênero masculino e no transformativo são do gênero feminino. Uma possível justificativa para essa afirmação seria a falta de representação feminina em muitos gêneros narrativos, 
que talvez levasse as fãs do gênero feminino a adotar essa postura mais anárquica em relação ao cânone, justamente para alcançar alguma representatividade.

Apesar de Hills (2015) discordar dessa classificação binária, considerando que ainda não há uma definição universal de fandom, essa tentativa de agrupá-los pode ser pertinente para entender as motivações dos fãs.

Tendo em mente toda informação colocada até agora, assumimos uma definição mais didática de fandom para melhor compreensão de sua atuação: fandoms são comunidades de fãs que compartilham produtos, experiências e trabalhos de seu objeto de veneração. Esse objeto de culto pode ser livros, filmes, seriados, bandas, cantores, histórias em quadrinhos (HQs), gibis, mangás (quadrinhos japoneses), animes (animação japonesa), reality shows, celebridades, entre outros. A produção de objetos (textuais ou não) e de sentidos é, portanto, intrínseca aos fandoms.

Matt Hills (2013), apoiado em conceitos de John Fisk, elenca três tipos de produtividade do fã, são eles: produtividade semiótica; produtividade de enunciação e produtividade textual. A produtividade semiótica ocorre no momento de recepção do objeto, consiste no significado que o indivíduo atribui ao objeto consumido. Desta forma, ela refere-se à cultura popular como um todo e não somente à cultura de fã (HILLS, 2013). A segunda produtividade refere-se à enunciação. A produtividade enunciativa está ligada à comunicação entre os fãs e tem caráter social; refere-se, portanto, ao compartilhamento dos significados, seja através da fala, da escrita digital, seja ainda no modo de se vestir, no corte de cabelo etc. Como essa produtividade ocorre apenas por relações sociais no interior do fandom, a circulação dos significados produzidos é limitada e, portanto, o capital cultural gerado é restrito (HILLS, 2013). Por último, a produtividade textual se refere a todos os produtos gerados no interior do fandom seguindo modelos preestabelecidos da cultura oficial. $\mathrm{O}$ fator econômico diferencia a produção do fandom da produção da cultura oficial e não a competência e/ou a habilidade do fã, pois os fãs não visam ao lucro quando se propõem a produzir conteúdo (HILLS, 2013).

O panorama da produtividade é alterado a partir da web 2.0, em que a web passa a ser participativa e todos os atores envolvidos têm a opção de 
produzir conteúdo. No contexto digital, as fronteiras entre as três produtividades se confundem e se mesclam e as três produtividades podem ocorrer ao mesmo tempo. A web 2.0 é um modelo de cultura participativa em que toda a produção textual, isto é, a criação de conteúdo, a participação em fóruns de discussão ou interações nas diferentes plataformas de sociabilidade do ambiente digital, é submetida a avaliações e verificações constantes pelos membros da comunidade. Essa interação define a criatividade coletiva, que têm como paradigmas a acessibilidade e o feedback contínuo (HILLS, 2013).

Esses sistemas de verificação garantem que o conteúdo produzido e divulgado atenda a algumas diretrizes de qualidade. Em relação à questão moral, a verificação garante que os textos não ofendam direitos humanos e correspondam à classificação indicativa. Por exemplo, os sites de produção de fanfictions contam com uma equipe de beta readers (corretores voluntários de ortografia, gramática e enredo) para melhorar a qualidade dos textos depositados no site.

As comunidades se fortalecem tendo como paradigma o compartilhamento - de materiais, competências, habilidades ou opiniões. A produção participativa estreita laços e cria identidades que moldam a imagem do fandom, o que contribui para sua perpetuação.

\section{Biblioteca pública e fandom: um diálogo possível}

No Manifesto IFLA/UNESCO (1994) sobre bibliotecas públicas, estão listadas as missões-chaves da biblioteca, entre elas: criar e fortalecer os hábitos de leitura nas crianças; estimular a imaginação e criatividade das crianças e dos jovens; facilitar o desenvolvimento da capacidade de utilizar a informação e a informática; possibilitar o acesso a todas as formas de expressão cultural das artes do espetáculo; fomentar o diálogo intercultural e a diversidade cultural. Dessa forma, compreende-se a biblioteca como o ambiente para pôr em prática as atividades dos fandoms por meio da mediação do profissional da informação.

A produção de conteúdo feita pelos fãs colaboradores engloba os mais diversos tipos de materiais, são eles: fanarts (desenhos, pinturas), fanzines (revistas), fanfilms (filmes), fanfictions (histórias, narrativas), além dos cosplays 
(caracterização do indivíduo como personagem de um cânone). A realização dessas atividades envolve competências manuais e digitais, de leitura e escrita, mobiliza habilidades criativas, lógicas e reflexivas, além de estimular a autocapacitação. No contexto da biblioteca, essas habilidades podem ser potencializadas a partir da reunião de pessoas com interesses em comum, do compartilhamento de competências e do acesso a materiais e oficinas que ajudem no desenvolvimento de tais habilidades.

Uma boa forma de implementar essas atividades na biblioteca é a ação cultural. Milanesi (2002) define ação cultural como as diferentes atividades ligadas às artes, sendo raramente desenvolvidas em bibliotecas, tais como: música, teatro, literatura, dança, ópera, exposição, recital, concurso literário, entre outros. Geralmente as atividades estão relacionadas a materiais que compõem o acervo da biblioteca; dessa forma, para a execução do projeto de ação cultural, é positivo que se reúna todo material disponível na instituição, com os mais diversos suportes (MILANESI, 2002).

A ação cultural é de extrema importância em BPs, principalmente porque utiliza diversas linguagens artísticas para promover a leitura. Em muitos locais a biblioteca representa a única instituição cultural disponível, por isso é necessário pensar em atividades que engajem os diferentes grupos de interesse que constituem a comunidade, tanto a leitora como a leitora em potencial (FUNDAÇÃO..., 2010).

Desenvolver atividades culturais também pode servir a outros propósitos, conforme listam Martins e Rocha (2017, p. 3):

[...] divulgação da própria biblioteca, [...] promoção de seus produtos e serviços, [...] acolhimento da comunidade e de suas necessidades, bem como o de mediação do acesso desta a bens culturais pouco disponíveis, o incentivo à reflexão sobre temas cotidianos, a manutenção das tradições e das memórias locais, etc.

Os profissionais das bibliotecas devem atuar na falta de profissional mais especializado, como agentes culturais, isto é, como os profissionais responsáveis por incentivar, planejar e organizar ações culturais (FUNDAÇÃO..., 2010). O responsável pela implantação da ação deve realizar um planejamento que seja participativo, ou seja, que envolva a comunidade, de modo a mapear grupos com interesses em comum. Ao se identificar com as atividades, a comunidade 
passará a utilizar esse espaço com mais frequência, o que gera comprometimento com a instituição e modifica a percepção do público em relação à biblioteca.

Além disso, ao agente cultural compete (FUNDAÇÃO..., 2010, p. 112):

- Sugerir e/ou escolher temas, e/ou captar o que está interessando à comunidade;

- $\quad$ Elaborar um projeto para cada tipo de atividade cultural;

- Definir os objetivos e metas a serem atingidos;

- Determinar datas e locais, materiais e equipamentos necessários;

- Verificar a necessidade de recursos financeiros extras e provê-los;

- Convidar pessoas da comunidade para participar das atividades culturais: artistas e artesãos locais, professores, músicos, escritores, padres, advogados etc;

- $\quad$ Projetar o marketing, ou seja, como divulgar os eventos;

- Analisar resultados após a realização dos eventos.

Portanto, são de responsabilidade desse profissional todas as etapas para implementação das atividades de ação cultural. O quadro a seguir lista diversas atividades que podem envolver ações culturais ao mesmo tempo que a biblioteca cumpre suas funções essenciais:

Quadro 1 - Funções culturais e educacionais da biblioteca pública

\begin{tabular}{|c|c|}
\hline $\begin{array}{l}\text { Funções da } \\
\text { biblioteca pública }\end{array}$ & Atividades culturais \\
\hline Promoção da leitura & $\begin{array}{c}\text { Concursos de leitura de contos e histórias, crítica de } \\
\text { livros, clube de leitura, curso de criatividade literária, } \\
\text { dramatização de leitura (teatro), feira de livros, hora do } \\
\text { conto, jogos literários, gincanas, lançamentos de livros, } \\
\text { mural de poesias, visita de escritores. }\end{array}$ \\
\hline $\begin{array}{l}\text { Centro do } \\
\text { aprendizado }\end{array}$ & $\begin{array}{l}\text { Cursos de curta duração (literatura, artesanato), telessalas } \\
\text { de alfabetização de adultos, palestras, discussões. }\end{array}$ \\
\hline Centro cultural & $\begin{array}{l}\text { Conferências, debates, exposições, feiras culturais, } \\
\text { maratonas culturais, mesas-redondas, varal cultural. }\end{array}$ \\
\hline Centro de lazer & $\begin{array}{l}\text { Apresentações musicais, clube do idoso, exibição de } \\
\text { filmes, audiovisuais ou multimídia, teatro, teatro de } \\
\text { fantoche e de sombras. }\end{array}$ \\
\hline
\end{tabular}


Quando comparado o Quadro 1 com os produtos gerados nos fandoms, listados no início desta seção, ficam evidentes as relações possíveis entre as atividades. Os produtos dos fandoms são produzidos de forma voluntária e espontânea; o fandom seria, nesse contexto, o grupo com interesse em comum que o agente cultural teria que descobrir. Visto que o fandom é constituído em sua maioria de pessoas já engajadas com um produto cultural, o desenvolvimento da ação cultural, provavelmente, será facilitado e o foco do agente cultural consistirá em localizar os possíveis integrantes do grupo e estabelecer comunicação com eles, além de ceder o espaço e mediar as atividades.

\section{Metodologia}

A presente pesquisa tem caráter descritivo-exploratório com abordagem qualitativo-quantitativa. Como ferramenta de coleta de dados, foi aplicado questionário por meio da ferramenta Formulários do Google. Como método para análise dos dados, foi utilizada a análise de conteúdo a partir de estudo estruturado do conteúdo.

A pesquisa descritiva, segundo Gil (2002, p. 42), tem “[...] como objetivo primordial a descrição das características de determinada população ou fenômeno ou, então, o estabelecimento de relações entre variáveis.”. Isto posto, essa técnica representou a melhor opção para esta pesquisa, uma vez que um de seus objetivos foi conhecer o atual posicionamento das bibliotecas públicas em relação aos fandoms através do questionário.

A pesquisa também é exploratória, pois a produção acadêmica que relaciona o fandom com as bibliotecas públicas é relativamente escassa no país. A pesquisa exploratória tem "[...] como objetivo proporcionar maior familiaridade com o problema, com vistas a torná-lo mais explícito ou a constituir hipóteses.” (GIL, 2002, p. 41).

Para a coleta de dados, foi escolhido o questionário com perguntas mistas, isto é, contendo perguntas discursivas, alternativas e de múltipla escolha. Este tipo de questionário "[...] é útil quando o investigador quer obter 
informação qualitativa para complementar e contextualizar a informação quantitativa obtida pelas outras variáveis.” (HILL M.; HILL A., 1998, p. 18).

A pesquisa é quantitativa, já que os dados foram analisados com o método estatístico. As pesquisas quantitativas, segundo Chizzotti (2018, p. 52): "[...] preveem a mensuração de variáveis preestabelecidas, procurando verificar e explicar sua influência sobre outras variáveis, mediante a análise da frequência de incidências e de correlações estatísticas.".

O caráter qualitativo desta pesquisa reside no fato de o questionário ser semiaberto, ou seja, houve espaço para o respondente aprofundar sua opinião descritivamente por meio de perguntas discursivas. As pesquisas qualitativas "[...] fundamentam-se em dados coligidos nas interações interpessoais, na coparticipação das situações dos informantes [...]. O pesquisador participa, compreende e interpreta." (CHIZZOTTI, 2018, p. 52).

Para análise dos dados coletados, foi utilizado o método de análise de conteúdo. Esse método consiste em fazer uma análise qualitativa a partir de dados quantitativos. Para Bardin (2011) a análise de conteúdo é um conjunto de instrumentos metodológicos que pretende, a partir de uma hermenêutica controlada, fazer inferências baseadas em dedução. Amado (2013) afirma que esse método utiliza o sistema categorial, isto é, separa o conteúdo expresso em categorias, e, a partir do referencial teórico do investigador, às categorias são atribuídas inferências. Essas inferências são as variáveis a serem analisadas dentro de cada categoria. Segundo Amado (2013), a análise de conteúdo se divide em estudo estrutural e estudo diferencial. Na presente pesquisa foi utilizado o primeiro estudo, que consiste na análise da ocorrência com vistas a medir a regularidade de determinado fenômeno. A partir desse estudo, pretendese "[...] descrever e elucidar características [...] das comunicações em análise [...]" (AMADO, 2013, p. 306).

Para o recorte de público do questionário, foram utilizados dados cadastrais extraídos do Sistema Nacional de Bibliotecas Públicas - SNBP. O SNBP é um órgão instituído em 1992 através de decreto presidencial, que o colocou como órgão subordinado à Fundação Biblioteca Nacional (SNBP, 2019). Após a extinção do Ministério da Cultura, ele atualmente está vinculado ao Ministério da Cidadania. O SNBP atua em seis eixos: assessoria técnica; 
Bruna Daniele de Oliveira Silva e Deise Maria Antonio Sabbag

instalação e modernização; formação de pessoal; qualificação de acervos; fomento à pesquisa e gestão da informação. Ele atua em nível federal e é o elo entre os 27 Sistemas Estaduais de Bibliotecas Públicas (SEBPs), de forma a fortalecer as políticas e as ações de promoção do livro e da leitura (SNBP, 2019).

Às bibliotecas públicas que apresentaram endereço de e-mail, foi enviado o questionário; as restantes, por questões logísticas (facilidade na coleta e armazenamento dos dados) e financeiras (custo zero no envio de e-mail em contraponto ao alto custo das chamadas telefônicas entre estados, que se apresentam como única alternativa ao e-mail) não foram consideradas para a coleta de dados.

No total, são 6.057 bibliotecas públicas cadastradas, mas muitas delas não apresentam endereço de e-mail e, além disso, os dados foram atualizados em 2015, então muitos endereços eletrônicos estavam desatualizados. Após montar-se uma planilha com os dados das bibliotecas que informam endereço de e-mail, chegou-se a uma amostra de 2.742 e-mails, representando 23 estados das cinco regiões do país, pois as bibliotecas de alguns estados e do Distrito Federal não apresentaram nenhum endereço eletrônico. Ao final da pesquisa, chegou-se a uma amostra de 111 respondentes.

\section{Resultados}

Após análise do questionário, o conteúdo foi dividido em três categorias e nove inferências, conforme quadro a seguir: 


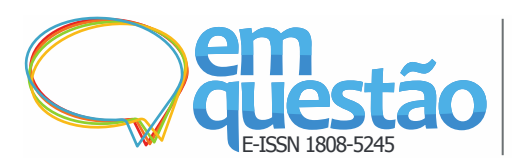

Fandom como instrumento de ação cultural: a produção participativa e o compartilhamento nas bibliotecas

públicas brasileiras

Bruna Daniele de Oliveira Silva e Deise Maria Antonio Sabbag

Quadro 2 - Categorias de análise

\begin{tabular}{|c|c|}
\hline Categorias & Inferências \\
\hline $\begin{array}{c}\text { Categoria 1: } \\
\text { Infraestrutura e serviços } \\
\text { das bibliotecas }\end{array}$ & Tipos de materiais pertencentes ao acervo das \\
bibliotecas
\end{tabular}

Fonte: Elaborado pelas autoras.

A Categoria 1, Infraestrutura e serviços das bibliotecas, inicia-se com a inferência Tipos de materiais pertencentes ao acervo das bibliotecas, que teve como objetivo listar os materiais que compunham o acervo, como demonstrado no Gráfico 1:

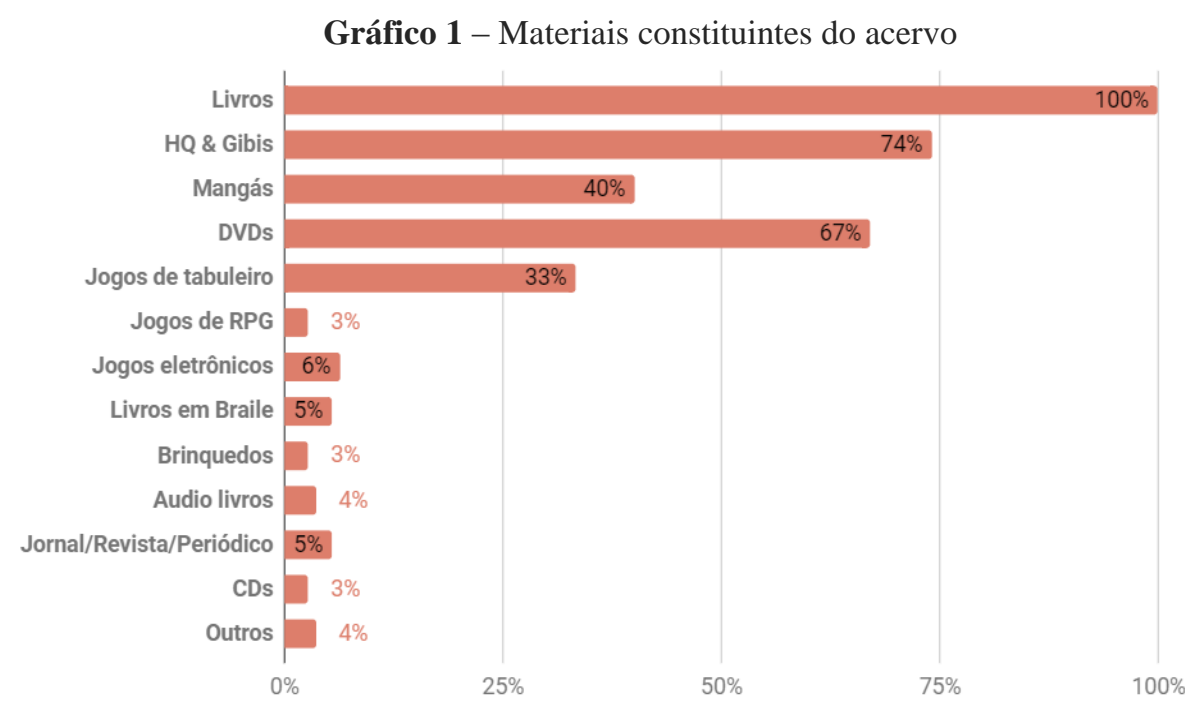

Fonte: Elaborado pelas autoras. 
Como esperado, todas as bibliotecas possuem livros em seu acervo. Outros materiais presentes em grande parte das bibliotecas são HQs e gibis (74\%) e mangás (40\%). Os fandoms das obras nesses suportes são numerosos e muito ativos nas comunidades e compõem boa parte do público que faz cosplay nos eventos. Além disso, as obras produzidas nesses suportes vêm sendo produzidas também em outros tipos de mídias, ou seja, são produtos transmídias, tais como as adaptações das HQs da Marvel para o cinema, a produção de animes (animações japonesas) adaptados a partir de mangás, entre outros.

A segunda inferência dessa categoria é Relação de serviços oferecidos pelas bibliotecas, com a qual se pretendeu verificar quais bibliotecas prestam serviços além dos básicos, tais como empréstimo e consulta.

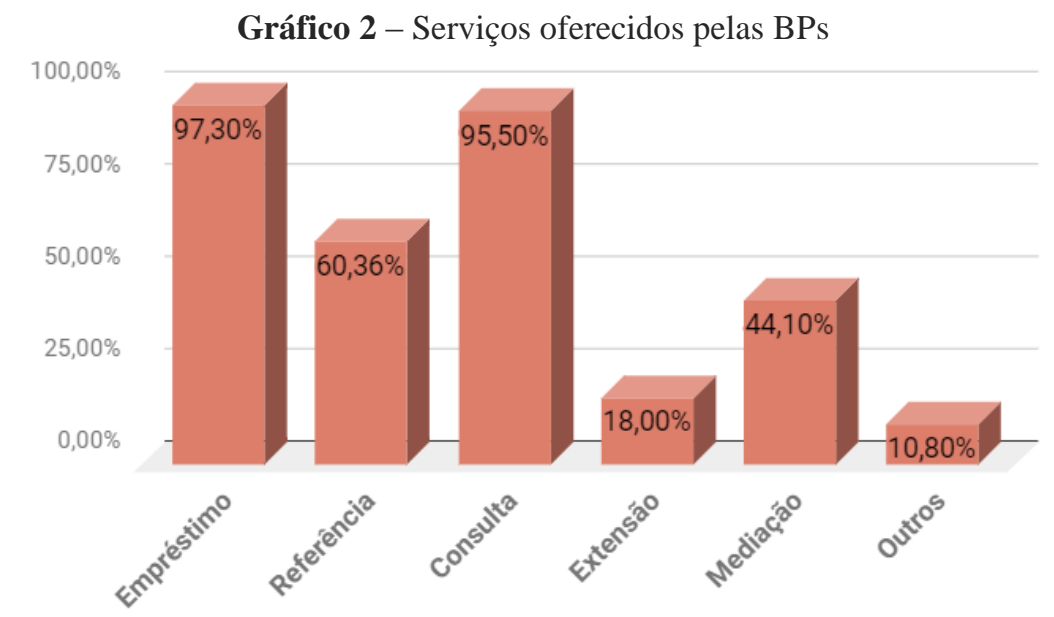

Fonte: Elaborado pelas autoras.

Os serviços mais oferecidos são empréstimo (97\%) e consulta (95\%), como já era presumido. Um total de três instituições não oferece serviço de empréstimo, do qual duas BPs e uma BP especializada. Outro serviço bastante expressivo é o serviço de referência, oferecido em $60 \%$ das bibliotecas, consiste em suprir necessidades informacionais e de auxílio a pesquisa. Menos da metade das bibliotecas desenvolve alguma atividade de mediação. Esse dado é preocupante, pois a mediação cultural, por exemplo, é a atividade que traz à biblioteca o usuário que não é muito ligado à leitura. A falta desse serviço, portanto, pode excluir boa parte do público em potencial. 
Iniciando a categoria Demanda e público das bibliotecas, temos a inferência Percepção da demanda dos usuários por novas atividades. Aqui o respondente foi questionado sobre sua percepção quanto a possíveis demandas dos usuários.

Gráfico 3 - Demanda do público por novas iniciativas/atividades na biblioteca

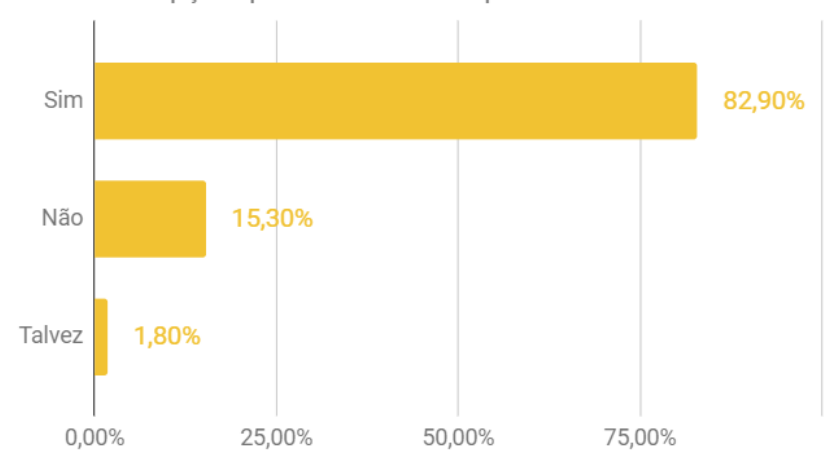

Fonte: Elaborado pelas autoras.

Para cerca de $83 \%$ dos respondentes, há demanda por novas iniciativas ou atividades na unidade. Os $15 \%$ que acreditam não existir demanda por novas iniciativas argumentam que a biblioteca não tem muitos usuários ou que a maior parte dos usuários é composta por um público específico, por exemplo, idosos que frequentam a unidade apenas para fazer empréstimo de livros. Alguns admitem não terem realizado um estudo para verificar se há demanda, mas afirmam que essa é a percepção geral. Outros dizem não saber se há demanda $(1,8 \%)$ por nunca terem feito uma pesquisa para descobrir isso.

Em questões discursivas, os respondentes expuseram os motivos de haver ou não haver demanda. Dentre as justificativas que negavam a existência de demandas nas BPs, estavam:

Devido não haver procura no momento. [sic] (RESPONDENTE 59)

Desinteresse. [sic] (RESPONDENTE 84)

A maioria dos usuários são idosos e a única demanda é por novos livros. (RESPONDENTE 93)

O interesse da comunidade nessas atividades é pequeno. (RESPONDENTE 104)

Nota-se que os respondentes 59, 84, 93 e 104, respectivamente, negam a demanda na unidade sem informarem se já foi desenvolvido um estudo de 
usuário para mapear possíveis demandas reprimidas, então fica em dúvida se realmente não existe demanda ou se não são oferecidas oportunidades de constituir novos públicos. Trata-se de um equívoco, já que as BPs devem caracterizar seus utilizadores a partir da identificação das necessidades da comunidade e já que essa identificação deve ser refeita periodicamente.

Conhecer a comunidade a que se serve é primordial para o funcionamento de uma BP. Em contrapartida às justificativas dos respondentes 84 e 93, as BPs devem oferecer serviços a grupos minoritários e com interesses diversos, e é, portanto, necessário criar iniciativas com o objetivo de fomentar a frequência de diferentes públicos, mesmo que haja outro grupo consolidado na unidade. É claro que as atividades de fandom não serão aplicáveis em todas as BPs por uma questão de cultura local, isto é, cada público terá uma necessidade distinta; no entanto, negar essa demanda antes de um estudo de comunidade é um engano.

Por outro lado, temos as justificativas apresentadas de haver demanda. Nota-se a mudança dos discursos no sentido de os bibliotecários já terem feito algum tipo de sondagem da comunidade ou de esses bibliotecários lembrarem alguma experiência anterior:

Existe demanda porque na cidade já existem ações nessa área que chamam público, acredito que basta a iniciativa e planejamento da nossa equipe para realizar um evento como esse. (RESPONDENTE 41)

Acredito que a demanda existe, pois já entrevistamos os leitores de mangás e de HQ e eles se interessaram. (RESPONDENTE 46)

Em outros tempos a biblioteca realizava atividades de música, batepapo com o autor entre outros. Alguns usuários cobram outras iniciativas nesse sentido. (RESPONDENTE 49)

Pelos anseios descritos pelos usuários. (RESPONDENTE 57)

Porque o público que se interessa por mangá, HQ, RPG usa bastante a biblioteca e pode se interessar por essas outras modalidades. (RESPONDENTE 60)

Pois são feitas avaliações constantemente. (respondente 68)

A biblioteca possui um grupo 'Jovem que lê', que junto com a equipe da biblioteca, desenvolveu o evento do Harry Potter e estão abertos $[s i c]$ a outras atividades. (RESPONDENTE 72)

Muitos respondentes, naturalmente, associaram os fandoms somente ao público jovem, e realmente, o público mais engajado nas atividades de fandom 
Bruna Daniele de Oliveira Silva e Deise Maria Antonio Sabbag

são os jovens. No entanto, se bem direcionadas, as atividades podem atender a todas as faixas etárias, principalmente em se tratando dos eventos que convergem diversas atividades. É importante lembrar que o fandom de Star Trek, um dos primeiros a ganhar notoriedade, tem suas origens nos anos 1960; o de Star Wars, nos anos 1980; Doctor Who, no mesmo período; portanto, existem fãs em todas as faixas etárias.

Em algumas respostas, reafirma-se que os serviços prestados devem acompanhar as transformações em torno da comunidade e na sociedade em geral, inclusive nos âmbitos da diversidade cultural e dos meios de comunicação (GILL, 2001):

As novas tecnologias motivam nos leitores novas iniciativas/atividades. (RESPONDENTE 90)

Acreditamos que há demanda porque a biblioteca tem reduzido os serviços ofertados nos últimos anos, restringindo-se às funções mais básicas da biblioteca pública e diminuído [sic] as iniciativas de ação cultural. (RESPONDENTE 95)

O atual usuário precisa de inovações na prestação de serviços. (RESPONDENTE 107)

Destaca-se aqui que um dos respondentes atentou para a questão da ação cultural que, como foi colocado no início, é um meio de engajar a leitura utilizando-se de diversas linguagens artísticas.

\section{A segunda inferência é Relação de públicos atendidos/público}

potencial, que teve como objetivos identificar os públicos mais atendidos atualmente e verificar se as unidades atendem a todos os públicos possíveis e quais os públicos negligenciados por falta de recursos da biblioteca, conforme os gráficos 4,5 e 6 , respectivamente:

Gráfico 4 - Públicos que frequentam a biblioteca

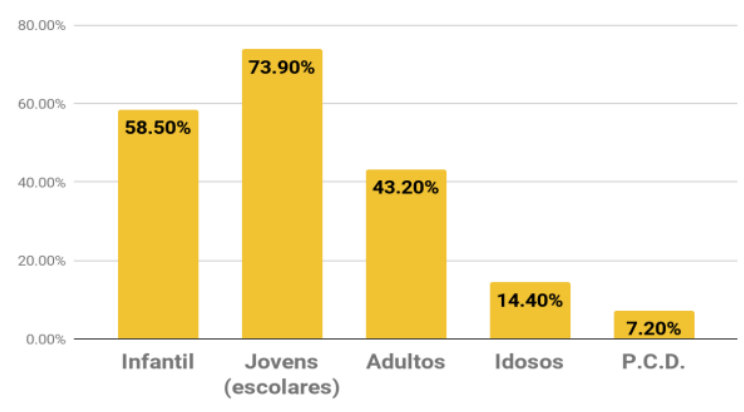

Fonte: Elaborado pelas autoras. 
Aqui foi proposta uma questão de múltipla escolha para o respondente elencar quais públicos constituem a maior parte de seu público geral. Como era esperado, $73 \%$ das bibliotecas têm os jovens entre os mais atendidos. Essa é uma tendência que vem sendo constatada em diversos estudos há décadas, pois muitas pessoas ainda veem a biblioteca como um simples auxílio às atividades escolares. É o que Suaiden (2000, p. 55) chama de "escolarização da biblioteca pública". O público infantil figura entre o mais atendido em $58 \%$ das unidades. É importante atentar para o público potencial que os pais dessas crianças representam, pois se houver atividades com as quais esses pais se identifiquem, eles também passarão a frequentar a biblioteca.

O próximo gráfico expõe quanto os respondentes julgaram que sua biblioteca atendia todos os públicos possíveis, considerando apenas os recursos e serviços atuais.

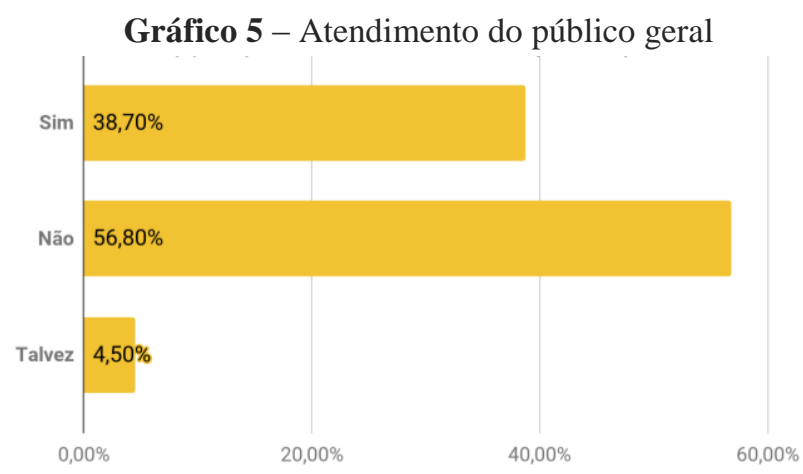

Fonte: Elaborado pelas autoras.

Quase $40 \%$ acreditam que a biblioteca atende todos os públicos de sua comunidade. Já 56,8\% dizem que não atende; em sua maioria alegam que não há estrutura ou recursos humanos suficientes para atender a todos, como evidenciado nas respostas discursivas:

A demanda de usuário é boa, porém faltam mais recursos. (RESPONDENTE 42)

Há demanda das unidades escolares do CEU, no entanto, não conseguimos atender por falta de recursos humanos para desenvolver os projetos. (RESPONDENTE 47)

Muitas pessoas procuram atividades diferenciadas, mais [sic] não [as] encontrando perdem o interesse pela biblioteca. (RESPONDENTE 73) 
Os discursos evidenciam que mesmo nas unidades em que há demanda, os públicos são negligenciados pela falta de recursos e, por isso, acabam não frequentando a biblioteca. As falas são importantes, pois expõem o descaso, a falta de representação dessas instituições frente às hierarquias administrativas, bem como em relação aos órgãos de representação como o SNBP.

O último gráfico dessa categoria demonstra quais públicos os participantes do questionário consideraram os mais negligenciados pelas BPs por falta de recursos ou serviços.

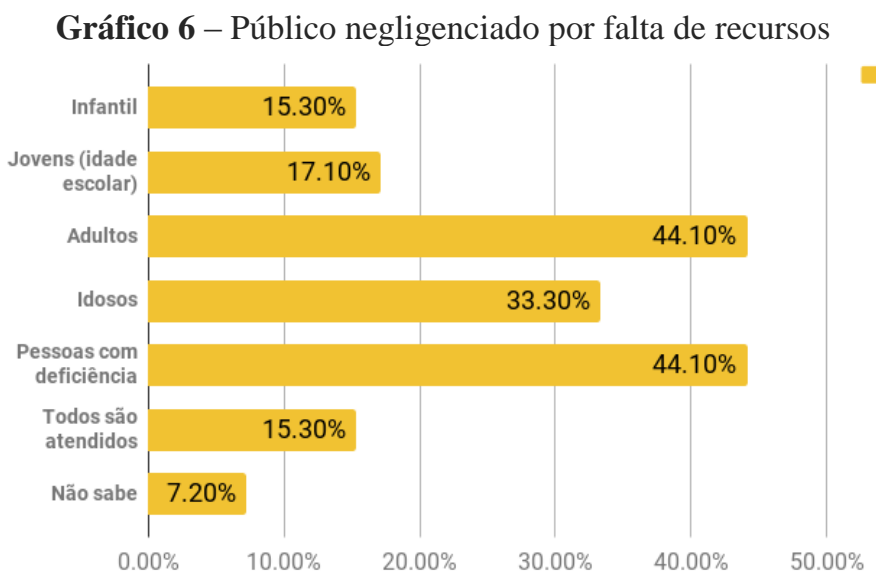

Fonte: Elaborado pelas autoras.

O público que foi apontado como mais negligenciado foram as pessoas com deficiência (PCD). A falta de adaptação para atender esse público em todas as esferas públicas é evidente; quando considerado um espaço que já é negligenciado para o público geral, o descaso fica ainda maior. Como foi visto no Gráfico 1, apenas 5\% dos respondentes afirmam que as BPs em que trabalham possuem livros em Braille. A exclusão já começa no acervo, falta adaptação para qualquer tipo de deficiência e a falta de atividades que integrem essa população agrava ainda mais a situação. Outro público bastante negligenciado são os adultos, que em sua maioria trabalham em horário comercial; como as BPs tendem a funcionar nesse período, os adultos acabam sendo excluídos. Apenas $15 \%$ afirmam atender todos os públicos possíveis.

Quando comparadas as porcentagens dos Gráficos 5 e 6, há uma inconsistência nas respostas. Enquanto, no Gráfico 5, aproximadamente 40\% dos respondentes afirmaram atender a todos os públicos, no Gráfico 6, em que 
foram listados todos os públicos, a porcentagem de respondentes que afirmam atender todos os públicos cai para 15\%. Essa inconsistência pode indicar que os respondentes, ao responder à questão representada pelo Gráfico 5, não atentou para todos os públicos que a biblioteca pública tem o dever de atender ou não tinha conhecimento deles todos.

A terceira categoria, Fandom e biblioteca, teve como objetivo verificar se os funcionários conhecem o conceito de fandom, se alguma biblioteca já desenvolve alguma atividade para fandoms, se há possibilidade de desenvolver alguma atividade para fandoms, quais empecilhos impediriam o desenvolvimento de uma atividade assim e quais benefícios essas atividades poderiam trazer à comunidade da biblioteca.

A primeira inferência, Conhecimento dos funcionários acerca do conceito de fandom, contabilizou os respondentes que conhecem o conceito, os que não conhecem e os que conhecem superficialmente, conforme o Gráfico 7:

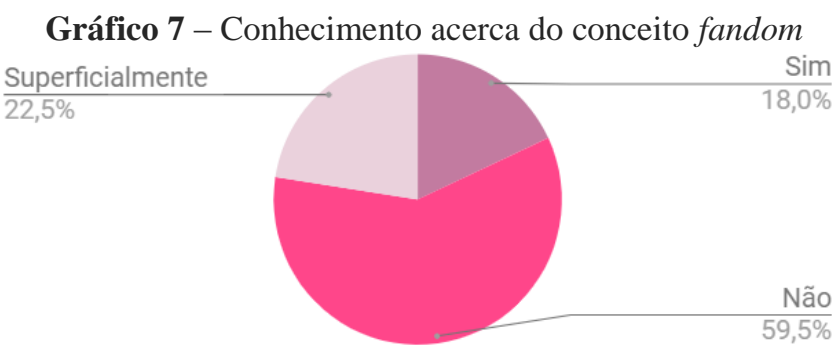

Fonte: Elaborado pelas autoras.

Mais da metade (60\%) dos respondentes não conhece o conceito de fandom, seguida de $22 \%$ que o conhecem superficialmente. Somente $18 \%$ conhecem de fato esse conceito. Já era esperada uma alta porcentagem de pessoas que desconhecessem o conceito, pois apesar de o termo não ser novo, ele ganhou notoriedade a partir da web 2.0. Os estudos de fandom relacionados à biblioteca são ainda mais recentes. Através de sua iniciativa Center for the future of libraries, a ALA (2016) produziu uma lista denominada Trends onde listou o fandom como uma das tendências para bibliotecas em 2016, enquanto no Brasil o assunto é ainda pouco estudado nessa correlação com as bibliotecas.

Em seguida, foi oferecida uma definição do termo fandom e foram mencionadas algumas atividades desenvolvidas nas comunidades de fãs. $\mathrm{O}$ resultado é analisado a partir da segunda inferência, Desenvolvimento de 
atividades de fandom nas bibliotecas. No Gráfico 8 indica-se a proporção de BPs que já desenvolvem algumas atividades de fandoms.

Gráfico 8 - Número de bibliotecas com atividades de fandom

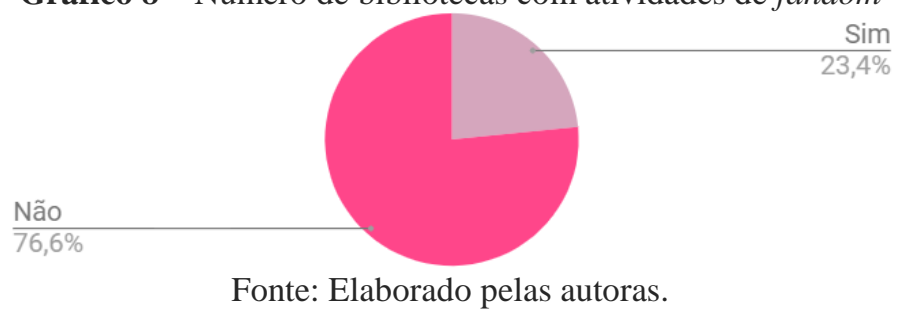

Com a porcentagem de participantes do questionário que desconheciam o conceito, não era esperado um número alto de bibliotecas que já desenvolvessem atividades relacionadas aos fandoms. Apenas 23\% das BPs desenvolvem alguma(s) atividade(s) listada(s) junto à conceituação. Nas justificativas, a resposta que apareceu com mais frequência foi a falta de conhecimento sobre fandoms. Apesar do desconhecimento das atividades, alguns respondentes se mostraram interessados em desenvolver essas iniciativas futuramente:

Até o momento não há material ou recursos para essas atividades. Porém, no projeto de modernização (Edital SEDACTEL $\mathrm{n}^{\circ}$ 27/2017) estão previstas aquisições de acervo e novas "atividades" que poderão ser consideradas como similares às citadas acima [atividades de fandom], em especial, o clube do gibi. [sic] (RESPONDENTE 31)

Não que seja impedida, mas é um assunto relativamente novo para nós e ainda não explorado por nossa biblioteca. Quem sabe futuramente viemos [sic] a trabalhar com o tema. Será interessante. (RESPONDENTE 37)

Não despertamos para esse tipo de atividade, que parece bem atraente para uma biblioteca. (RESPONDENTE 97).

O poder público só despende recursos financeiros a uma BP se o serviço que se propõe prestar for considerado relevante; além disso, o orçamento apresentado precisa ser bem justificado (FUNDAÇÃO..., 2010). A falta de recursos públicos desmotiva os funcionários, essa desmotivação leva a serviços cada vez mais precários e serviços mais precários afastam os usuários da biblioteca. Assim, cria-se um ciclo que deixa a biblioteca com cada vez menos protagonismo na comunidade. 
Quando o problema de falta de recursos é aliado a outros problemas que vão desde a hierarquia administrativa pouco solícita ou resistente a mudanças, passando por inconsistência no quadro de funcionários devido à mudança da gestão pública, até a população que vê a BP como uma instituição passiva, isto é, como depósito de livro, desenvolver novas atividades fica praticamente inviável, conforme demonstram os relatos abaixo:

Assumi a direção da biblioteca há um ano e desde lá venho fazendo algumas modificações, atualizações e inserções de programas e projetos up-to-date. Este ano, por razões políticas de mudança de governo, tive que interromper o meu planejamento de 4 anos e a partir de agosto, não mais estarei aqui, na direção. (RESPONDENTE 2)

[...] Estou aqui há 2 anos e meio, mas só há 6 meses me sinto um pouco mais à vontade para fazer coisas diferentes, depois da saída da coordenadora que tinha aqui. A comunidade aqui está acostumada com uma biblioteca pública que só está aberta, e mais nada. Então, ainda é muito difícil atrair público. [...] Acabei de fazer um curso de extensão sobre HQs e fanzines para ter mais conhecimento para criar coisas que atraiam o público. [...] Até porque o caminho da leitura é difícil mesmo, e isso faz parte da nossa profissão. [...] Creio que o que pode me atrapalhar um pouco, além de às vezes faltar material [...], é a própria resistência da população do entorno com a biblioteca. [...] Além disso, soma-se o fato de que as pessoas já têm uma resistência natural com leitura e biblioteca (creio que no país inteiro e mais ainda nas periferias). (RESPONDENTE 45)

Toda atividade a ser realizada na biblioteca precisa antes ser submetida para o departamento de curadoria do Centro Cultural [...]. Há muita burocracia nesse sentido, para que alguma atividade possa ser desenvolvida. (RESPONDENTE 49)

Na verdade 'motivos'. Começando por estarmos com limitações de acesso à tecnologia no que ser [sic] refere a COMPARTILHAR. Falta mais compreensão dos gestores públicos e falta de conhecimento $[s i c]$ por parte do técnico de informática quanto a essa limitação tecnológica. Creio que em bibliotecas públicas acesso a vídeos [...] (vídeos da TV CULTURA, por exemplo) deveriam ser livremente acessados $[s i c]$. Aqui na Prefeitura [...] tal acesso está bloqueado. Também com esta limitação, os trabalhos desenvolvidos, que serão realizados aqui OU pela nossa biblioteca pública não poderão ser transmitidos ou mostrados ao público via internet. [...] Creio que com tantas barreiras de acesso à informação [...] a biblioteca [...] perde muito! (RESPONDENTE 25)

A biblioteca passou muito tempo sem bibliotecário, passando a contar com o profissional da área somente neste ano. Nestes três meses a prioridade tem sido o tratamento do acervo [...]. Aos poucos estamos desenvolvendo projetos de leitura voltados para crianças e jovens em idade escolar, mas ainda não colocamos em prática. (RESPONDENTE 28) 
Os relatos têm certo tom de denúncia, dando uma dimensão da atual situação dessas instituições e evidenciando que a biblioteca pública do Brasil precisa de uma renovação em todas as esferas, enquanto instituição que depende de recursos públicos, enquanto espaço da comunidade, no âmbito da representação dos sistemas estaduais e federal e inclusive enquanto local de trabalho de seus profissionais. A biblioteca pública no Brasil parece abandonada em todas essas esferas, ainda que haja profissionais que seguem resistindo e tentando fazer a diferença.

Segundo a Fundação Biblioteca Nacional (2010, p. 44), “[...] o responsável pela biblioteca deve ser um bibliotecário [...] habilitado legalmente [...]”, pelo menos nos municípios com mais de 5000 habitantes. É função desse profissional planejar, obter recursos, delegar serviços e manter a equipe motivada, assim como “[...] estimular a consciência social, [aplicar sua] flexibilidade, adaptabilidade, capacidade de análise, curiosidade mental, iniciativa, uma boa dose de bom humor e criatividade [...]" (FUNDAÇÃO..., 2010, p. 45). Se essas recomendações fossem seguidas, provavelmente não haveria tantos problemas recorrentes como falta de profissionais, recursos e iniciativa, como sugerem as seguintes justificativas:

Há apenas uma auxiliar de biblioteca atuando no local. (RESPONDENTE 10)

Falta de materiais e do profissional. (RESPONDENTE 12)

Rotatividade de funcionários (RESPONDENTE 57)

A atividade pode ser realizada, falta a iniciativa. (RESPONDENTE 41)

Por não termos uma pessoa formada na área. (RESPONDENTE 70)

Alguns respondentes alegaram que não desenvolvem atividades de fandom porque não há demanda:

Até o momento não houve procura ou interesse pela comunidade. (RESPONDENTE 20)

Não há interesse da comunidade. (RESPONDENTE 53)

Demanda não detectada. (RESPONDENTE 76)

Não existe interesse por parte da comunidade. (RESPONDENTE 78) 
Falta de identificação de demanda específica para este fim. (RESPONDENTE 80)

Falta de público. (RESPONDENTE 82)

[...] Nunca foi requisitado na biblioteca. (RESPONDENTE 93)

No entanto, como já foi dito, as BPs também devem agir como agentes culturais; isto significa promover atividades com diferentes expressões artísticas. A partir das justificativas expressas, é possível perceber que essas unidades não atentam para essa função. Como prova disso, a justificativa abaixo demonstra que o público mais envolvido com os fandoms frequenta a biblioteca e mesmo assim ele é encarado pela instituição como um público sem interesse por outras atividades:

Os usuários apenas são estudantes que utilizam o espaço para a realização de trabalhos escolares. (RESPONDENTE 71)

Fica evidente o desconhecimento, por parte dos funcionários, quanto à função da BP e das atribuições do profissional dessas instituições.

No Gráfico 9 são mostradas quais atividades são desenvolvidas pelas BPs que indicaram já desenvolver atividade de fandom.

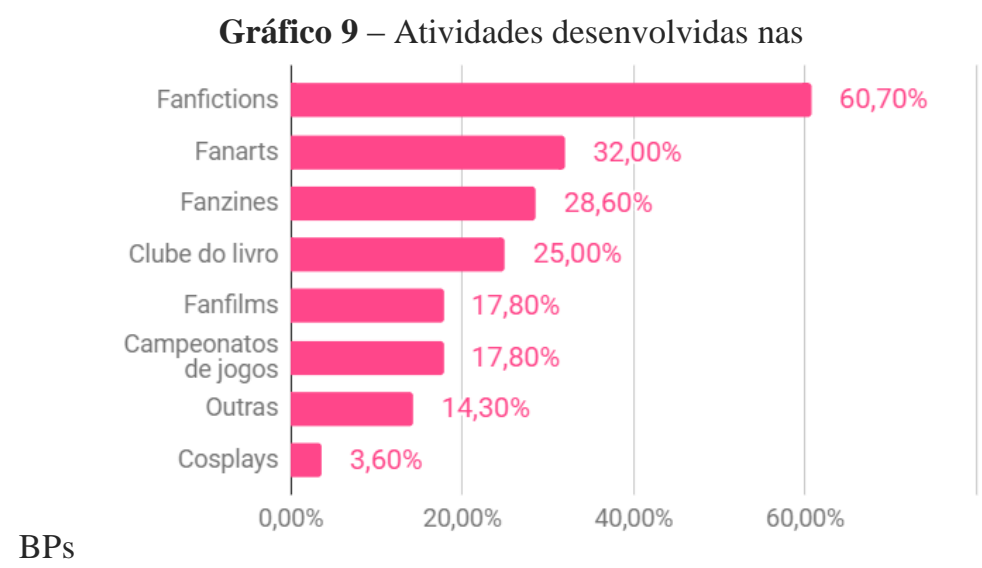

Fonte: Elaborado pelas autoras.

A atividade desenvolvida na maior parte das BPs é a fanfiction (60\%), não por acaso, já que é a atividade mais ligada a leitura e já que é, além disso, uma atividade que exige poucos recursos de quem escreve (folha e caneta ou software de computador) e da biblioteca (livros, quadrinhos e outros materiais do acervo). Outras atividades bastante desenvolvidas são: fanarts (desenhos), com 32\%; fanzines (revistas), com $28 \%$ e clube do livro com 25\%. Entre as 
atividades listadas na opção Outras, destacam-se: concurso de leitura, torneio de literatura fantástica - jogos e atividades em torno de Harry Potter, oficinas de cordel e cursos voluntários.

\section{A próxima inferência é Atividades de fandom possíveis com os} recursos atuais e buscou verificar a possibilidade de as BPs desenvolverem tais atividades e as atividades que é possível realizar com os recursos de cada biblioteca.

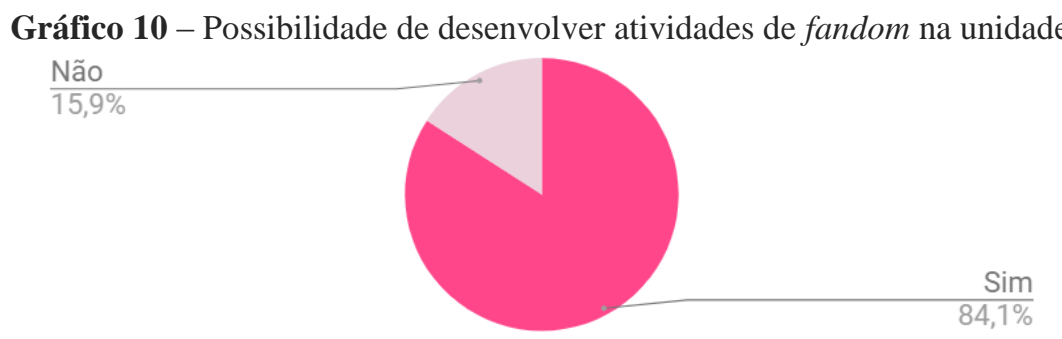

Fonte: Elaborado pelas autoras.

Cerca de $85 \%$ dos respondentes acreditam ser possível desenvolver ao menos uma atividade na biblioteca apenas com os recursos atuais. No Gráfico 11 é listado quais atividades os respondentes acreditam serem passíveis de desenvolvimento em suas unidades.

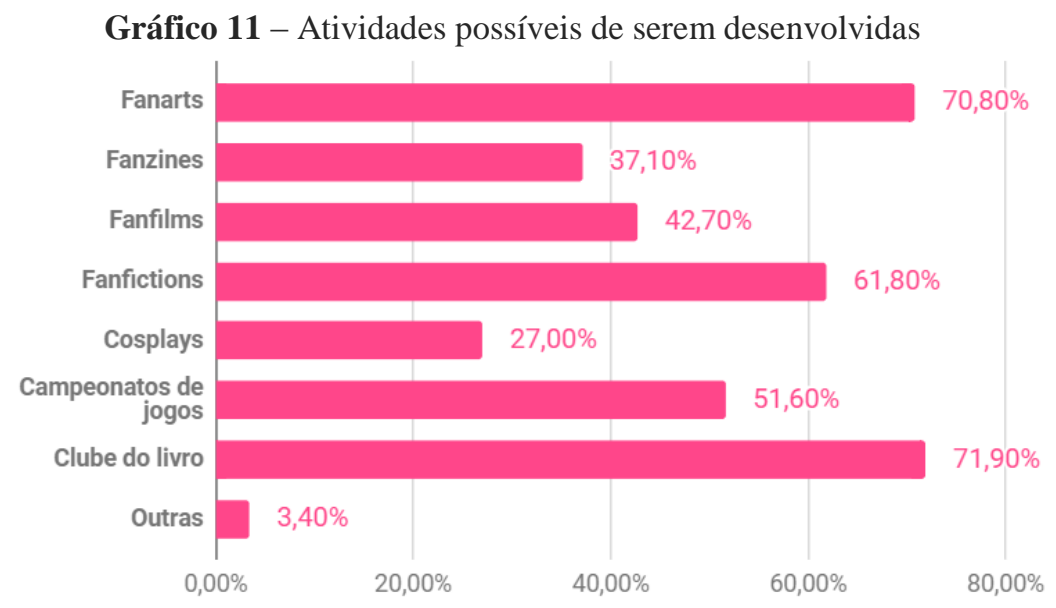

Fonte: Elaborado pelas autoras.

Entre as atividades com maiores condições de serem desenvolvidas nas BPs, estão: clube do livro (cerca de $72 \%$ dos respondentes afirmam ser possível) e fanzine (cerca de $71 \%$ dos respondentes afirmam ser possível). As fanfictions aparecem em seguida, sendo possível pôr em prática a atividade em cerca de $62 \%$ das BPs. Curiosamente as fanfictions não são a escolha da maioria, apesar 
de serem a atividade mais presente nas BPs que já realizam atividades de fandom. Esse dado pode ser explicado por dois motivos: o primeiro é que é mais difícil que a escrita desperte engajamento do público em geral, pois é uma atividade que demanda tempo e concentração maior; o segundo motivo é que para desenvolver atividades com fanfictions, as BPs precisam oferecer oficinas que demandam conhecimentos específicos, como ortografia, gramática, escrita criativa, entre outros, nas quais, provavelmente, seriam necessárias parcerias com profissionais de diferentes áreas. Um dado interessante é que os fanfilms são mais apontados como uma opção viável nas BPs do que as fanzines, o que supreende, já que as fanzines são revistas informais criadas a mão e os fanfilms demandam maiores recursos tecnológicos e maior letramento digital do usuário. Entre as atividades citadas na opção Outras, destacam-se: oficinas de HQs, feira de fanzines e troca de livros.

A quarta inferência é Atividades de fandom possíveis com mais recursos. Nesta parte os respondentes foram questionados sobre as atividades que poderiam ser implantadas nas BPs caso a unidade contasse com maiores recursos em geral, como explanado no gráfico abaixo:

Gráfico 12 - Atividades possíveis de serem desenvolvidas com recursos

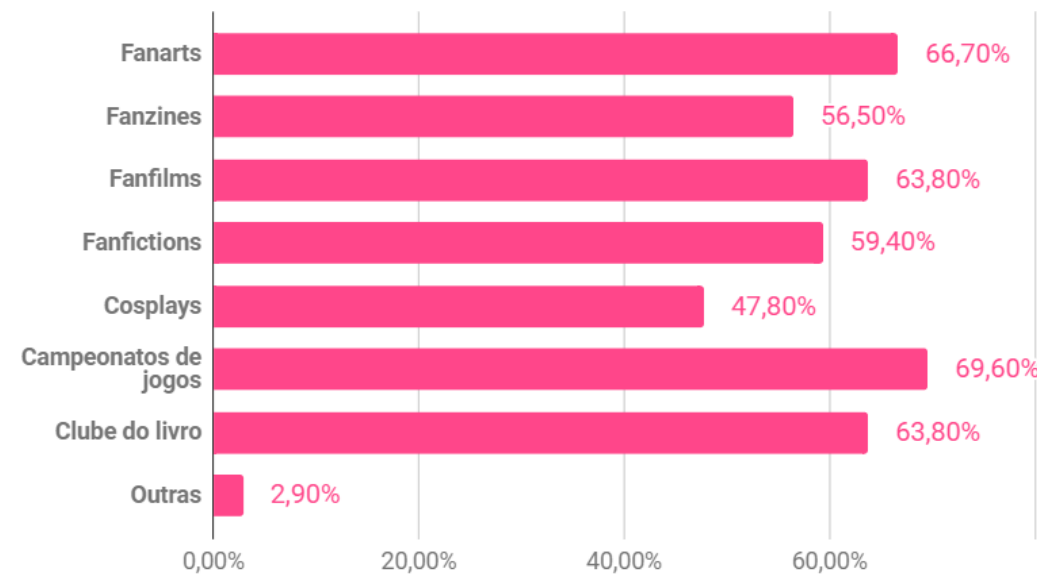

Fonte Elaborado pelas autoras.

Com aplicação de recursos, as seguintes atividades têm maiores condições de serem realizadas: fanzines, que foram de $37 \%$ para 56\%; fanfilms, que saltaram de $42 \%$ para $63 \%$ e cosplay, saindo de $27 \%$ para $47 \%$. Os campeonatos de jogos, que eram possibilidade em $51 \%$ das BPs, alcançaram 
69\%. Entre as atividades citadas na opção Outras, destacam-se: exposições, atividades musicais, oficinas e campeonatos.

A última inferência, Percepção dos benefícios das atividades dos fandoms à comunidade, buscou verificar se os respondentes acreditam que essas iniciativas trazem benefícios a BP e quais seriam eles.

Gráfico 13 - Possibilidade das atividades de fandoms beneficiar a comunidade

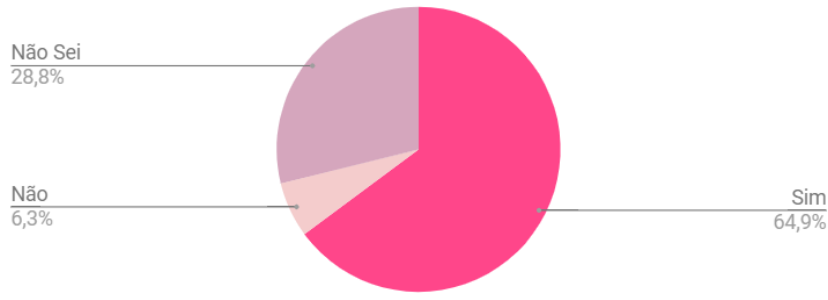

Fonte: Elaborado pelas autoras.

Quase 65\% dos respondentes acham interessante desenvolver atividades de fandom em suas unidades; $28 \%$ não sabem responder, pois não têm conhecimento suficiente sobre o assunto, e apenas 6\% não acham as atividades relevantes para sua unidade.

Foi pedido aos respondentes que apontassem quais benefícios os fandoms trariam à unidade:

A disseminação da cultura entre os vários públicos da biblioteca e ainda despertando [sic] o interesse de novos, já é um benefício incalculável. Outro [benefício] que colabora para a BP cumprir com suas 12 missões descritas pelo 'Manifesto da UNESCO para a biblioteca pública' [...]. [...] Quero sugerir que tal treinamento (capacitação) seja ofertado AMPLAMENTE para todas as bibliotecas de nosso país, começando por todas as bibliotecas públicas ligadas à FBN e ao SNBP. (RESPONDENTE 25)

Além da satisfação do público que busca por este tipo de atividade, ocupar a biblioteca faz com que ela crie vida. Você potencializa seu uso, aproxima o público e uma vez que eles estejam ambientados, fica mais fácil de fazê-los perceber os serviços que a biblioteca pode oferecer. A partir do momento que a biblioteca faz parte da rotina da comunidade, cria-se uma rede de fortalecimento junto ao poder público, porque os usuários que passam a usufruir de serviços adequados se comprometem com a defesa desse espaço. (RESPONDENTE 28)

Poderia atrair mais usuários para a biblioteca e contribuir com o fomento da profissão de bibliotecário, pois desta forma a comunidade iria entender o papel do bibliotecário. (RESPONDENTE 40) 
As justificativas acima salientam a consciência, por parte dos profissionais, da finalidade da BP e de sua importância para a comunidade que a cerca.

Aos que responderam que as atividades de fandom não trariam benefícios à unidade e aos que não souberam responder, foi pedido que justificassem:

Necessito conhecer experiências de equipamentos culturais que aplicam as atividades do fandom para analisar melhor. (RESPONDENTE 83)

Seria interessante para a biblioteca, só que no momento não tem como acontecer. A biblioteca funciona em um prédio tombado pelo IPHAN, está muito deteriorado, precisando de reparos urgentes e está tudo parado. (RESPONDENTE 97)

Falta de conhecimento do assunto o que [sic] acarreta falta de recursos humanos para executar a atividade. (RESPONDENTE 100)

Novamente, a justificativa mais recorrente foi a falta de conhecimento sobre o assunto ou falta de capacitação para desenvolver tais atividades. De fato, é possível concluir que de maneira geral a proposta do fandom nas BPs foi bem aceita; no entanto, para colocá-la em prática, essas instituições terão que superar problemas que persistem há várias décadas, desde a imagem que a população tem desses lugares, até a negligência do poder público com os equipamentos culturais, negligência que acarreta falta de recursos financeiros, humanos e estruturais.

\section{Considerações finais}

Confrontando-se realisticamente o cenário atual das BPs brasileiras, perceberse-á que o desenvolvimento das atividades dos fandoms nessas instituições será de difícil, porém não impossível, realização. Para dar início a esse movimento, antes é necessário o conhecimento do conceito de fandom. Isso pode ocorrer através da inserção do tema nos eixos de formação de pessoal e de qualificação de acervos do SNBP. Na formação de pessoal, podem-se promover cursos com essa temática de forma a preparar os profissionais para desenvolver essas atividades em suas unidades. Já na qualificação do acervo, o SNBP poderia promover acervos com materiais diversificados, incluindo materiais de uso comum nos fandoms. 
A partir da conscientização dos profissionais acerca do tema, o SNBP poderia incentivar as bibliotecas com maiores recursos e infraestrutura, tais como as estaduais e a biblioteca demonstrativa do SNBP, a começarem a desenvolver tais iniciativas, de forma a servirem de referências para as demais. Além disso, é necessário um engajamento maior dos órgãos de classe no sentido de garantir que as bibliotecas sejam geridas por profissionais da Biblioteconomia e que as BPs tenham mais autonomia em suas gestões.

As BPs em âmbito local devem se adequar às necessidades informacionais e culturais da comunidade a que cada uma serve. Para isso é necessário conhecer seus usuários e instigar novos usuários. Com o intuito de desenvolver novas atividades, é preciso que se invista em estudo de usuário. Diversificar atividades e materiais é essencial para atrair novos públicos. Dessa forma, estabelecer parcerias com artistas e profissionais locais para realização de oficinas e cursos de interesse da comunidade, buscar doações de materiais, entre outras medidas, é fundamental para que a unidade cumpra, na medida do possível, o papel de transformação social da biblioteca pública.

O fandom é apresentado como um meio para pôr em prática essa nova perspectiva da biblioteca. Por se constituírem de indivíduos com interesses comuns e engajados com diferentes atividades artísticas, os fandoms têm o potencial de mobilizar grupos de interesse em torno da BP. A união das atividades dos fandoms à BP pode garantir que a unidade cumpra alguns de seus compromissos implícitos, tais como engajar a leitura e a escrita, desenvolver competências e integrar a comunidade.

\section{Referências}

AMERICAN LIBRARY ASSOCIATION (ALA). Trends. 2016. Disponível em:

http://www.ala.org/tools/future/trends\#Organization\%20and\%20Classification\% 20of\%20Trends. Acesso em: 7 abr. 2019.

AMADO, João. Manual de investigação qualitativa em educação. Coimbra: Imprensa da Universidade de Coimbra, 2013.

BARDIN, Laurence. Análise de Conteúdo. São Paulo: Edições 70, 2011. 
CHIZZOTTI, Antônio. Pesquisa em ciências humanas e sociais. 12. ed. São Paulo: Cortez, 2018.

FUNDAÇÃO Biblioteca Nacional. Biblioteca Pública: princípios e diretrizes. 2. ed. Rio de Janeiro: Fundação Biblioteca Nacional, 2010.

GIL, Antonio Carlos. Como elaborar projetos de pesquisa. 4. ed. São Paulo: Atlas, 2002.

GILL, Philip. Os serviços da biblioteca pública: directrizes da IFLA/UNESCO (2001). Lisboa: Editorial Caminho: Associação Liberpólis, 2001.

HILL, Manuela Magalhães; HILL, Andrew. A Construção de um questionário. Lisboa: Dinâmia'CET-IUL: FCT, 1998.

HILLS, Matt. Fiske's ‘textual productivity' and digital fandom: web 2.0 democratization versus fan distinction. Participations, Newcastle Upon Tyne, v. 10, n. 1, p. 130-153, 2013.

HILLS, Matt. O fandom como objeto e os objetos do fandom. [Entrevista cedida a] Clarice Greco. MATRIZes, São Paulo, v. 9, n. 1, p. 147-163, 2015.

INSTITUTO PRÓ-LIVRO. Retratos da Leitura no Brasil. 4. ed. São Paulo: Instituto Pró-livro; Rio de Janeiro: IBOPE, 2016. 142 slides. Disponível em: http://prolivro.org.br/home/images/2016/Pesquisa_Retratos_da_Leitura_no_Bra sil_-_2015.pdf. Acesso em: 20 mar. 2019.

JENKINS, Henry. Invasores do Texto: fãs e cultura participativa. Nova Iguaçu: Marsupial, 2015.

MANIFESTO IFLA/UNESCO sobre bibliotecas públicas. [S.l.]: IFLA, 1994. Disponível em: https://www.ifla.org/files/assets/publiclibraries/publications/PL-manifesto/pl-manifesto-pt.pdf. Acesso em: 10 abr. 2019.

MARTINS, Ana Carolina de Melo; ROCHA, Tânia Regina da. Três esferas: proposta para planejamento de ações culturais. In: ENCONTRO NACIONAL DE PESQUISA EM CIÊNCIA DA INFORMAÇÃO, 18., 2017, Marília. Anais... Marília: UNESP, 2017.

MILANESI, Luis. Biblioteca. São Paulo: Ateliê Editorial, 2002.

OBSESSION_INC. Affirmational fandom vs. Transformational fandom. Dreamwidth, [s.l.], 1 jun. 2009. Disponível em: https://obsessioninc.dreamwidth.org/82589.html. Acesso em: 10 abr. 2019.

SUAIDEN, Emir José. A biblioteca pública no contexto da sociedade da informação. Ciência da Informação, Brasília, v. 29, n. 2, p. 52-60, maio/ago. 2000. 
SISTEMA NACIONAL DE BIBLIOTECAS PÚBLICAS (SNBP). Sobre. 2019. Disponível em: http://snbp.cultura.gov.br/sobre/. Acesso em: 05 abr. 2019.

\title{
Fandom as an instrument of cultural action: participatory productivity and sharing in Brazilian public libraries
}

\begin{abstract}
Brazilian public libraries are often regarded as warehouses that serve only a select part of society. In contrast, fandoms consist of individuals with common interests, and their members collaborate in their activities. This article aims to examine the relation of fandoms to Brazilian public libraries and to determine, after data analysis, whether fandoms' activities are applicable to these institutions. This study has descriptive and exploratory character and takes both qualitative and quantitative approaches. For data collection, a questionnaire was applied by means of Google Forms. The method of analysis was categorical content analysis based on a structured content study. The results showed that $59 \%$ of respondents weren't familiar with the concept of fandom, $82 \%$ believed that there was a demand for new library activities and $84 \%$ believed that it was possible to develop fandom's activities with just the current resources. Fandom activities are directly related to reading, writing and to the development of several important skills, such as information and digital literacies. Therefore, the implementation of such activities in public libraries, besides encouraging the use of the space it represents, can engage readers and the community and promote sociability, thereby becoming an instrument of social transformation.
\end{abstract}

Keywords: Public Libraries. Fandom. Cultural action. Participatory culture. Collaborative work.

Recebido: 13/05/2019

Aceito: 26/10/2019 